\title{
Trail Phenomena in Connexion with Serratia Phages and Marcescin-like Activities
}

\author{
By H. STEIGER \\ BE Mikrobiologie im FB Biologie, Johann Wolfgang Goethe-Universität, \\ Siesmayerstrasse 70, D-6000 Frankfurt am Main, Federal Republic of Germany
}

(Received 8 July 1977; revised II September 1977)

\section{INTRODUCTION}

Further observations are reported here concerning the unusual trail-shaped protuberances of phage lysis emerging from spots of lysogenic cultures of Serratia marcescens $\mathrm{HY}$ (referred to as HY) placed on indicator layers (Steiger, 1973). Protuberances of similar appearance in lawns of Bacillus subtilis are also described; these were produced by overlaid HY cells, although were independent of the presence of the two native prophages $\psi$ and $y$.

\section{METHODS}

Bacteria and bacteriophages. These are listed in Table $\mathbf{I}$.

Media and procedures. Complete media and general cultivation conditions were as described by Steiger, Müller \& Bauer (1972). Soft agar for trail formation contained $0.3 \%(\mathrm{w} / \mathrm{v})$ agar for $S$. marcescens and $0.5 \%(\mathrm{w} / \mathrm{v})$ agar for B. subtilis, the latter supplemented with $\mathrm{I} .5 \%(\mathrm{w} / \mathrm{v})$ glucose to inhibit sporulation. Measurement of phage adsorption was by the method of Steiger et al. (1972), except that chloroform treatment was in NB to avoid a slight inactivation of phage $\kappa$.

\section{RESULTS AND DISCUSSION}

\section{Indication of the involvement of phage carrier bacteria in trail formation}

The appearance of trails in an $S$. marcescens lawn around drops of overnight cultures that had dried on the plate surface was not confined to cultures lysogenic for the phages $y$ or $\kappa$; it also occurred after mixing bacteria resistant to phage adsorption with one of these phages. Thus, a mixture of $\mathrm{HY}^{\mathrm{r}}$ and $\kappa\left(5 \times 1 \mathrm{O}^{9}\right.$ bacteria $\mathrm{ml}^{-1}$ from an overnight culture, $5 \times 10^{6}$ to $5 \times 10^{7}$ phages $\mathrm{ml}^{-1}$ ) spotted on an HY plate caused $\kappa$ trails; this occurred even with mutants $\kappa \mathrm{CI} 39, \kappa \mathrm{VI} 64$ or $\kappa$ int 69 that cannot lysogenize. Similarly trails of $\psi$ or $y$ in an $\operatorname{HY}(\psi, y)^{-}$lawn emerged from drops of $\operatorname{HY}(\psi, y)^{-} \psi^{\mathrm{r}} y^{\mathrm{r}}$ or $\operatorname{HY}(\psi, y)^{-} \psi^{\mathrm{r}} y^{\mathrm{r}} \kappa^{\mathrm{r}}$ with added $\psi$ or $y\left(5 \times 10^{5}\right.$ to $5 \times 10^{6}$ phages $\left.\mathrm{ml}^{-1}\right)$. However, when $\kappa \mathrm{cI} 39$ was added to the strain resistant to three phages, only trails of tiny violet dots on the red-pigmented indicator $\mathrm{HY}$ were observed. If trails had been caused by the motility of bacteria, the capacity of mutants defective in lysogenization might be due to a type of non-lysogenic carrier state of phage within the bacteria. Such carriers must have been derived from the indicator lawn since the bacteria of the drop were phage resistant. Addition of specific antiserum $\left(\mathrm{K}=5 \mathrm{~min}^{-1}\right)$ to drops of cultures lysogenic for $y$ or $\kappa$ almost completely prevented trail formation.

Although phage particles were always found in the trails, these might be due to the activity of marcescin-like substances produced by the swarmers. However, this was excluded, at least for $\kappa$, by the use of the $\mathrm{su}^{+}$strain HYw3 I9, lysogenized with $\kappa$ susS 74 . When spotted on a zone of soft agar with added $\mathrm{su}^{+}$indicator, placed on an $\mathrm{su}^{-}(=\mathrm{HY})$ soft agar plate, the trails ended at the limit of the su- indicator and continued in a second concentric $\mathrm{Su}^{+}$soft agar ring. Thus, lysis of bacteria due to phage infection is apparently necessary for 
Table I. Bacterial and phage strains

Strain

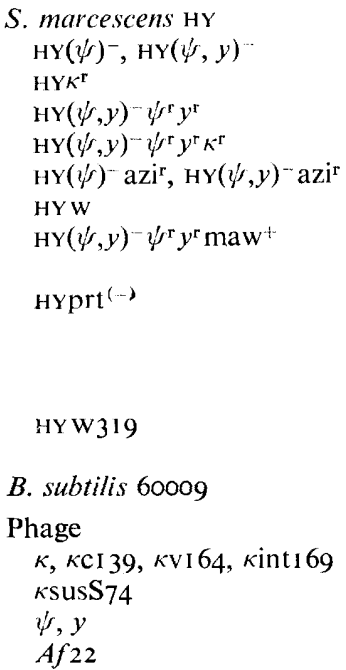

Notes

Possesses native prophages $\psi$ and $y$, red pigmented

Cured of, respectively, $\psi$ and both $\psi$ and $y$ (Steiger, 1973)

Resistant to phage $\kappa$

Resistant to both $\psi$ and $y$, although selected as resistant to $y$

$\kappa$-resistant derivative of $\mathrm{HY}(\psi, y)^{-} \psi^{\mathrm{r}} y^{\mathrm{r}}$

Resistant to sodium azide $\left(100 \mu \mathrm{g} \mathrm{ml}^{-1}\right.$ )

Unpigmented, hydroxylamine induced

Unpigmented, spontaneous mutant of $\operatorname{HY}(\psi, y)^{-} \psi^{r} y^{r}$ with a marcescin activity (maw) against HY strains

Protease activity at $30{ }^{\circ} \mathrm{C}$ about one-third that of $\mathrm{HY}$ as measured in the supernatants of overnight cultures according to Millet (1970), $N$-methyl- $N^{\prime}$-nitro- $N$-nitrosoguanidine induced

Possesses a nonsense suppressor (Winkler, Kopp-Scholz \& Haux, 1970)

See Bautz Freese \& Freese (1964)

Grown on HY (Steiger et al., I972)

Grown on HYw319 (Winkler et al., 1970)

Grown on HY( $\psi, y)^{-}$(Steiger, I973)

Grown on $\mathrm{HY}(\psi, y)^{-}$, not forming lysogenic cells, obtained from H. E. Prinsloo via U. Winkler

trail formation. Even when soft agar plates were prepared without indicator and the lysogenic culture was spotted directly on the plate, trails appeared in a surrounding su ${ }^{+}$ring $^{-}$ (Fig. I $a$ ), but there were no plaques in such a ring when, instead of the lysogen, a drop of sus lysate $\left(6 \times 10^{9}\right.$ phages $\mathrm{ml}^{-1}$ in NB) was placed on indicator-free soft agar. This suggests that diffusion of spontaneously induced phage from the central spot to the $\mathrm{su}^{+}$ring followed by carrier cell formation is less likely than migration of carrier bacteria, formed by reinfection of some non-lysogenic segregants in the culture drop.

The appearance of the trails depended on the phage type. A mixture of $\operatorname{HY}(\psi, y)^{-} \psi^{\mathrm{r}} y^{\mathrm{r}}$ with $y$ gave rise to continuous trails, whereas a mixture with $\psi$ yielded chains of dot-like plaques in an $\mathrm{HY}(\psi, y)^{-}$lawn. $\kappa$ trails obtained with $\mathrm{HY}^{\mathrm{r}}$ ended in dot plaques in an $\mathrm{HY}$ lawn. This could be explained by swarmers splitting off non-swarming bacteria along their path, and only occasionally producing new swarmers as indicated by branching of trails.

\section{Different ability of strains to provoke trail formation}

The following experiments indicate that the trails reflect a negative chemotactic response of swarmers to gradients of an inhibitory substance produced by the culture drops. These drops contained about 10 times more bacteria than similar areas of the indicator layer. When a drop of indicator was placed adjacent to a drop of bacterial culture emitting trails in a lawn of the same indicator, the trails ended on a line between the drops (Fig. I $b$ ). On the other hand, when droplets of NB suspensions of $\psi, y$ (each $5 \times 10^{6}$ phages $\mathrm{ml}^{-1}$ ), $\kappa \mathrm{cl}^{3} 39$ $\left(5 \times 10^{7}\right.$ phages $\left.\mathrm{ml}^{-1}\right)$ or $A f 22\left(\mathrm{I} \times 10^{6}\right.$ phages $\left.\mathrm{ml}^{-1}\right)$ were placed on indicator plates near drops of $\mathrm{HY}(\psi, y)^{-} \psi^{\mathrm{r}} y^{\mathrm{r}} \kappa^{\mathrm{r}}$, trails emerged from the averted edges of the lysis spots, indicating gradients around the culture spots. With HY $^{\mathrm{r}}$ drops, however, only droplets of $\mathrm{HY}^{\mathrm{r}}$ (mixed with $\kappa \mathrm{cl} 39$ ) or those of $\mathrm{HY}(\kappa)$ showed such oriented trail emission.

Whether or not $\kappa \mathrm{cI} 39$ was added to a drop of $\operatorname{HY}(\psi, y)^{-} \psi \mathrm{r}^{\mathrm{r}} y^{\mathrm{r}} \kappa^{\mathrm{r}}$, trails emerged from surrounding $\kappa \mathrm{CI} 39$ droplets on HY plates. Therefore, this strain produced a gradient substance in regard to $\kappa$, although trail formation by mixtures with $\kappa \mathrm{cr} 39$ was strongly impaired. An explanation for this might be that culture drops produce an additional substance involved in the formation of carrier bacteria. With $\operatorname{HY}(\psi, y)^{-} \psi^{r} y^{r} \kappa^{r}$ the level of this sub- 

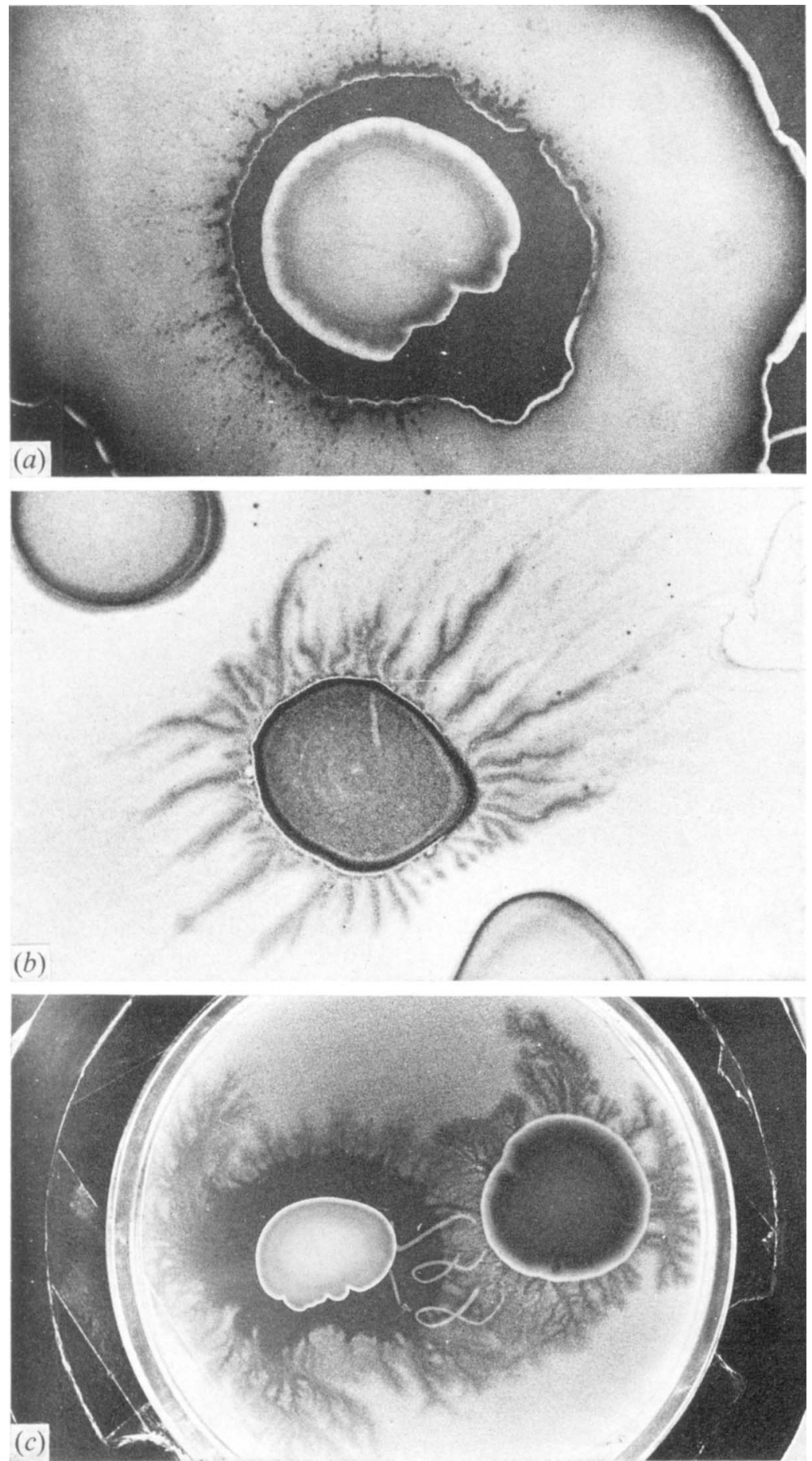

Fig. I. (a) $\kappa$ trails in a zone of soft agar with added $\mathrm{su}^{+}$indicator around a drop of $\mathrm{su}^{+}(\kappa \mathrm{susS} 74)$ placed on soft agar without bacteria.

(b) Clipped trails emerging from a drop of $\mathrm{HY}^{\prime}(\psi, y)^{-} \psi^{\mathrm{r}} y^{\mathrm{r}}$ mixed with $y$, with drops of indicator $\mathrm{HY}(\psi, y)^{-}$on either side.

(c) Protuberances emerging from drops of HY (right) and $\mathrm{HYprt}^{(-)}$(left) on indicator B. subtilis 60009 . 
stance might be higher than with $\mathrm{HY}^{\mathrm{r}}$, so that ordinary formation of $\kappa$ carrier cells might be disturbed in the drop itself, but might occur in surrounding lysis spots due to diffusion. Since $\mathrm{HY}(\psi, y)^{-} \psi^{\mathrm{r}} y^{\mathrm{r}} \kappa^{\mathrm{r}}$ did not interfere with $\kappa$ trail formation when mixed with equal numbers of $\mathrm{HY} \kappa^{\mathrm{r}}$, provided with $\kappa \mathrm{cI} 39$, or with $\mathrm{HY}(\kappa), \mathrm{HY} \kappa^{\mathrm{r}}$ or $\mathrm{HY}(\kappa)$ bacteria might moderate the efficiency of that substance. The $\kappa$-sensitive wild-type HY, however, did interfere in such mixtures, probably due to products of lysis, and gradients could no longer be demonstrated.

In the examination of chemicals that might influence trail development, $y$ trails emitted from $\mathrm{HY}(\psi)^{-}$drops were found to be 'attracted' by spots of a saturated sodium azide solution. To test whether the trails follow the direction of increasing growth inhibition caused by the poison, gradient plates with azide $\left(20 \mu \mathrm{g} \mathrm{ml}^{-1}\right)$ in the upper part were overlaid with soft agar containing $\mathrm{HY}(\psi, y)^{-} \mathrm{azi}^{\mathrm{i}}$ indicator. When $\mathrm{HY}(\psi)^{-} \mathrm{azi}^{\mathrm{r}}$ drops were placed near the azide-free end of the plates the lateral branches of the emerging $y$ trails appeared to be aligned with the gradient.

\section{Trail formation by $S$. marcescens in lawns of B. subtilis}

Trail-shaped protuberances emerged from HY drops placed on soft agar plates with B. subtilis 60009 indicator (Fig. I $c$ ), whereas the HY derivatives $\mathrm{HY}$ W or $\mathrm{HY}(\psi, y)^{-} \psi^{\mathrm{r}} y^{\mathrm{r}} \mathrm{maw}^{+}$ were inactive. Since $\mathrm{HY}(\psi, y)^{-}$was also active, neither of the two native prophages is involved in trail formation. A marcescin A-deficient spontaneous mutant of the HY substrain w903 of Timmis \& Winkler (1973) was also active. Hence the possible participation of this marcescin is excluded.

When HYprt $^{(-)}$was used instead of HY, growth was undetectable in a zone around the culture drop, whereas turbid trails emerged into the outer region. $\operatorname{HY}(\psi, y)^{-} \psi^{\prime} \mathrm{r} y^{\mathrm{r}}$ behaved similarly but has not yet been investigated further. Pronase mixed into the soft agar (I $\mathrm{mg} \mathrm{ml}^{-1}$, Calbiochem) prevented the formation of the clear zone of $\mathrm{Hyprt}^{(-)}$whereas the trails were unaffected. Trypsin (I $\mathrm{mg} \mathrm{ml}^{-1}$, Boehringer), active against marcescin B (Prinsloo, 1966), had no effect when added to the plates. The results obtained with the marcescin A-deficient mutant and with trypsin are consistent with the findings of Eichenlaub \& Winkler (1974) that B. subtilis is sensitive to neither marcescin A nor B. The absence of the clear zone for HY is most probably due to its proteolytic activity, acting like the added pronase in case of $\mathrm{HYprt}^{(-)}$. Therefore, the strong growth inhibition with $\mathrm{HYprt}^{(-)}$may be caused by a protein excreted by the bacteria in the drop.

The nature of the protuberances with $B$. subtilis is still obscure although their formation may be due to swarmers. Attempts to isolate Serratia bacteria or an agent from them forming plaques on B. subtilis have failed. Filtrates (Millipore SLGS $0.22 \mu \mathrm{m}$ ) prepared from HY or HYprt ${ }^{(-)}$soft agar plates caused some attenuation of growth in spot tests on $B$. subtilis indicator but lacked such activity when prepared from liquid cultures. Incubation of the respective filtrates with trypsin or pronase $\left(\mathrm{I} \mathrm{mg} \mathrm{ml} l^{-1}\right.$ ) for $\mathrm{I} \mathrm{h}$ at $37^{\circ} \mathrm{C}$ had no effect, suggesting that the filtrates contained the agent involved in trail formation. The enzymes themselves did not inhibit $B$. subtilis growth at the concentration applied. The filtrates showed a bacteriostatic rather than a bacteriocidal effect when mixed with growing B. subtilis.

I thank Professor R. W. Kaplan for helpful discussion, and the Deutsche Forschungsgemeinschaft for financial support. 


\section{REFERENCES}

Bautz Freese, E. \& Freese, E. (1964). Two separable effects of hydroxylamine on transforming DNA. Proceedings of the National Academy of Sciences of the United States of America 52, I289-I 297.

Eichenlaub, R. \& WinkleR, U. (I974). Purification and mode of action of two bacteriocins produced by Serratia marcescens HY. Journal of General Microbiology 83, 83-94.

Millet, J. (I970). Characterization of proteinases excreted by Bacillus subtilis Marburg strain during sporulation. Journal of Applied Bacteriology 33, 207-219.

Prinsloo, H. E. (I966). Bacteriocins and phages produced by Serratia marcescens. Journal of General Microbiology 45, 205-2I 2.

STEIGER, H. (1973). Genetic studies with two pro- phages naturally resident in Serratia marcescens HY. Molecular and General Genetics 122, 345-352.

Steiger, H., Müller U. \& Bauer, G. (I972). Nonreceptivity for $\kappa$ phage of $\kappa$-lysogenic Serratia and reactions to superinfection of receptive cells with a mutant prophage. Molecular and General Genetics 114, 358-367.

Timmis, K. \& Winkler, U. (I973). Gene dosage studies with pleiotropic mutants of Serratia marcescens superactive in the synthesis of marcescin $\mathrm{A}$ and certain other exocellular proteins. Molecular and General Genetics 124, 207-2 I 7.

Winkler, U., Kopp-Scholz, U. \& Haux, CH. (I970). Nonsense mutants of Serratia phage kappa. I. Their isolation and use for proving circular linkage of the phage genes. Molecular and General Genetics 106, 239-253. 